\title{
PKM Pendampingan Guru dan Admin dalam Penggunaan Aplikasi Computer Base Tese (CBT) di SMP Ma'had Islam Semarang
}

\author{
Supriyanto ${ }^{1}$, Vivi Vira Viridianti ${ }^{1}$ \\ ${ }^{1}$ Universitas Widya Husada Semarang \\ Email : Supriyanto0156@gmail.com
}

\begin{abstract}
ABSTRAK
Ujian atau test merupakan cara untuk melihat hasil proses pembelajaran atau transfer ilmu yang dilakukan setelah proses pembelajaran sudah selesai. Ujian dilakukan beberapa cara diantaranya melalui responsi atau tanya jawab, terulis dan praktik. Cara ujian tersebut mempunyai banyak kelebihan dan kekurangan masing-masing. Ujian tertulis yang biasa disebut paper base test (PBT) memerlukan media kertas dan koreksi. Koreksi membutuhkan waktu, kemungkinan kesalahan sangat tinggi akibat kelelahan manusia. SMP Ma'had Islam dalam menjalankan ujian masih menggunakan paper base test (PBT) sehingga koreksi membutuhkan waktu dan biaya untuk pangadaan kertas. Aplikasi komputer dapat menyelesaikan kebutuhan tersebut diatas. Teknologi infromasi menggunakan aplikasi xampp, mysql dan aplikasi ujian diterapkan SMP Ma"had Islam tersebut, pembelajaran maupun diterapkan untuk ujian secara realtime yaitu computer base test (CBT). Kepraktisan ujian berbasis komputer yang melibatkan guru dan admin mengisi soal, memasukan siswa, matakuliah dan jadwal ujian.. Soal ujian dapat diatur secara acak untuk tiap komputer, waktu dapat diatur untuk buka dan tutup saat ujian sehingga kerahasiaanya dapat terjaga dan langsung dikoreksi oleh komputer untuk dapat melihat hasilnya. CBT di mitra dapat beroperasi dengan baik, dengan CBT hasil ujian dapat dikoreksi dengan cepat dan akurat. CBT dapat mengurangi biaya untuk pengadaan kertas dan efisien waktu.
\end{abstract}

Kata kunci: computer base test, intranet, lan

\section{ABSTRACT}

Exams or tests are a way to see the results of the learning process or knowledge transfer that is carried out after the learning process has been completed. The test is carried out in several ways, including through response or question and answer, written and practical. This test method has many advantages and disadvantages of each. The written exam which is commonly called a paper base test (PBT) requires paper media and corrections. Correction takes time, the probability of error is very high due to human fatigue. SMP Ma'had Islam in carrying out exams still uses paper base tests (PBT) so corrections require time and money for paper procurement.

Computer applications can solve the above needs. Information technology uses the xampp, mysql application and the examination application is applied to the Ma"had Islam Middle School, learning or being applied to realtime exams, namely computer base test (CBT). The practicality of computer-based exams that involve teachers and admins filling in questions, entering students, courses and exam schedules .. Exam questions can be randomly set for each computer, time can be set to open and close during the exam so that the confidentiality can be maintained and corrected by the computer to can see the results.

CBT in partners can operate well, with CBT test results can be corrected quickly and accurately. CBT can reduce costs for paper procurement and is time efficient.

Keywords: computer base test, intranet, lan 


\section{PENDAHULUAN}

Pembelajaran merupakan transfer ilmu dari nara sumber atau guru kepada penerima atau siswa. Transfer ilmu berhasil atau tidak membutuhkan parameter-parameter tertentu, misalkan dengan tanya jawab materi yang telah diberikan, melalui ujian yaitu mengerjakan soal terkait materi yang disampaikan dan dikerjakan di buku atau kertas tertentu. Mitra melakukan pembelajaran secara rutinitas dalam pembelajaran. Pelaksanaan ujian mitra masih menggunakan kertas yang membutuhkan kertas untuk soal ujian. Siswa tidak bisa mengetahui hasil dari ujian setelah selesai. Membutuhkan waktu untuk koreksi ujian.

Computer base test (CBT) merupakan teknologi untuk dapat mengatasi hal tersebut dengan aplikasi yang telah di desain atau koding untuk kebutuhan ujian online. Aplikasi ini telah banyak dishare ke situs-situs tertentu tinggal melakukan modifikasi untuk keperluan ujian tersebut disesuaikan dengan kebutuhan yang ada. Ujian dengan cbt ini membutuhkan beberapa persiapan hardware dan software. Hardware diantaranya unit komputer, smartphone, akses point atau jaringan local area network (LAN) dan internet. Software membutuhkan installasioperating system, xampp, php, sql dan browser.

Permasalahan mitra belum mengaplikasikan CBT secara intranet. Mitra masih menggunakan aplikaisi online dan sebagian masih menggunakan kertas sehingga membutuhkan biaya untuk pengadaan kertas. Kerahasiaan soal kurang terjaga karena bias dilihat peserta ujian. Kurang akurat dalam koreksi soal. Membutukan waktu untuk koreksi.
Melalui pelatihan penggunaan aplikasi CBT ini diharapkan dapat menyelesaikan permasalahan mitra dana menambah wawasan aplikasi CBT.

Sumber daya manusia(SDM) guru dan admin mampu menggunakan CBT karena semua sudah menggunakan labtop dan handpone. SMP Ma'had Islam juga sudah mempunyai laboratorium yang sudah terkoneksi jaringan local area networking, siswa sebagian besar sudah memiliki handphone, ujian juga bisa dilaksanakan di laboratorium komputer yang sudah ada.

\section{METODE PELAKSANAAN}

Pelaksanaan pengabdian kepada masyarakat bermula dari ijin kemitra diperbolehkan atau tidak pengabdian ini ternya mendapatkan sambutan positif dan diperbolehkan. Pengabdian dilaksanakan dengan praktik langsung mengisi aplikasi yang telah disiapkan, praktik ini dilaksanakan di tempat mitra yaitu SMP Ma"had Islam Semarang. Pengabdi memberikan pelatihan praktik dengan mitra mengenai pengoperasian dan pengaturan computer base test, pengaturan ini mulai dari pengisian guru, soal dan pengaturan ujian yang akan dilaksanakan. Memasukkan siswa dan password untuk login. Manager kelas mengatur jadwal ujian dan matapelajaran.

Pelatihan dengan praktik langsung dan hasilnya bisa dilihat langsung. Mitra memfasilitasi laboratorium komputer dan mengkoordinasikan dengan tenaga terkait yaitu admin sekolah, guru matakuliah yang sudah disiapkan soal tiap-tiap guru. Masa pandemi covid 19 tidak bisa menghadirkan siswa-siswi disimulasikan dengan guru merangkap siswa sekaligus menguji bentuk soal yang telah diinput di sistem. 


\section{HASIL DAN PEMBAHASAN}

Hasil pelaksanaan pemngoperasian CBT ini sebagai berikut :

\section{Admin}

Admin telah mengisi dan mengaktifkan siswa dan guru. Matakuliah telah diseting sesuai dengan guru mata pelajaran. Masing-masing bagian telah diaktifkan agar bisa masuk dalam sistem ini. Hasil dari setingan dan input admin tentang siswa sebagai berikut :

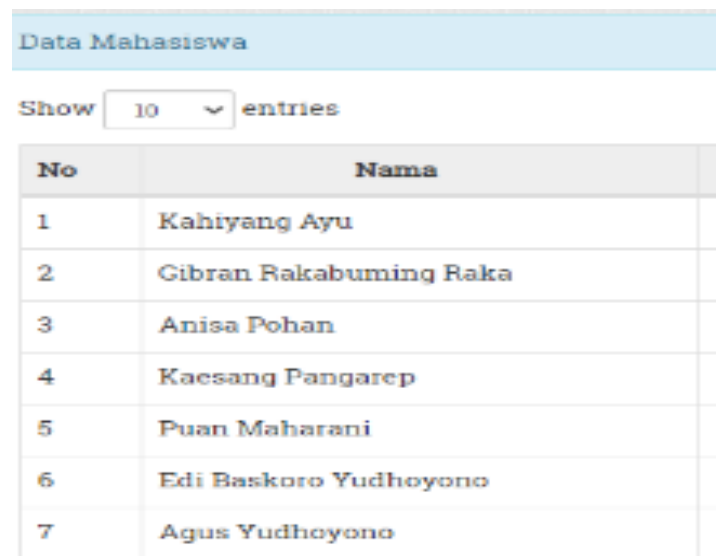

Tabel 1 Siswa

Tabel 1 daftar siswa yang sudah masuk disistem CBT dari tabel tersebut ada menu aksi dengan pilihan edit untuk memperbaiki data siswa. Pilihan aksi aktifkan user untuk mengkatifkan siswa biar bisa ikut ujian. Reset password digunakan untuk mengembalikan password kebentuk sama dengan user siswa. Hapus pilihan ini untuk menghapus siswa dari sistem CBT, user yang dihapus tidak bisa ikut ujian lagi maupun akses ujian CBT.

Hasil dari input dan pengaturanguru oleh admin terlihat pada tabel 2 sebagai berikut :

Tabel 2 Daftar guru

\begin{tabular}{|l|l|l|}
\hline Data Dosen & \\
\hline Show & $10 \quad v$ entries & NIP (Username) \\
\hline No & Nama & 1004 \\
\hline 1 & Tes & 1003 \\
\hline 3 & Erik Maulana & 1002 \\
\hline 4 & Dr. Abdulrahman Wahid & 1000 \\
\hline 5 & Ir. Joko Widodo & 1001 \\
\hline
\end{tabular}


Tabel 2 dalam menu aksi makul diampu wajib diisi dengan pilihan matapelajaran yang diampu oleh guru yang bersangkutan.
Hasil dari input dan pengaturn matapelajaran oleh admin pada tabel 3 sebagai berikut :

Tabel 3. Mata pelajaran



Hasil dari input dan pengaturan matapelajaran untuk guru oleh admin seperti tabel 4 centrang dimatapelajaran menunjukkan guru tersebut dapat mengampu seluruh matapelajaran yang ada yaitu bahasa Indonesia, bahasa inggris, matematika dan ipa sebagai berikut :

Tabel 4 Guru pengampu matakuiah

Setting Mata Kuliah

$\checkmark$ Bahasa Indonesia $\square$ Bahasa Inggris $\square$ Matematika $\square$ IPA

\section{Simpan Tutup}

Pengaturan ini akan menghubungkan guru dengan matapelajaran yang diampu, guru dapat mengajar lebih dari 1 mata pelajaran dengan cara mencentrang matapelajaran yang diampu.

\section{Guru}

Sistem CBT ini bagian guru atau pengajar harus login dengan user dan password yang telah diberikan oleh admin. Guru tidak bisa masuk ke CBT bila belum didaftar dan diaktifkan oleh admin. Setelah login guru bisa mulai dengan membuat soal sebagai berikut: 


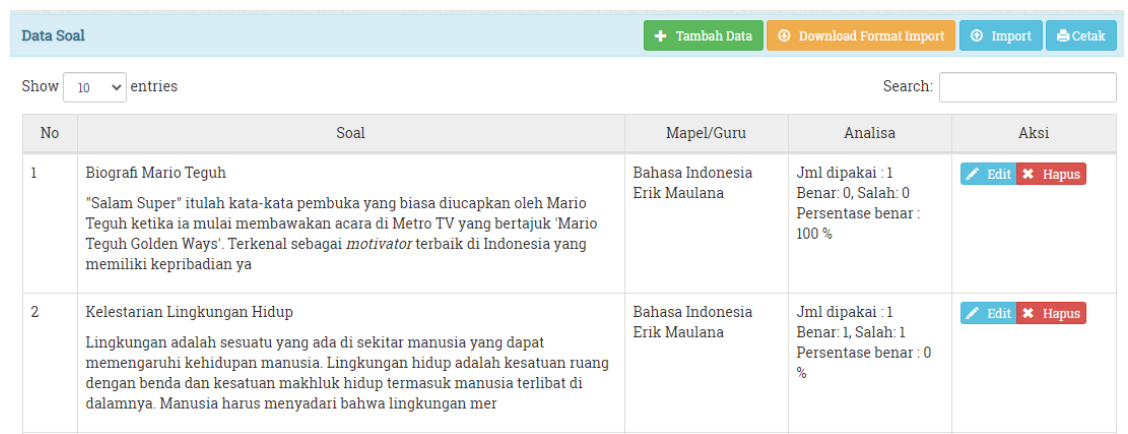

\section{Gambar Form input soal}

Guru setelah membuat soal tersebut gambar 9, berikutnya membuat jadwal ujian dan memberikan token yang otomatis tampil kepada siswa gambar 10 berikut :

\begin{tabular}{|c|c|c|c|c|c|c|}
\hline \multicolumn{6}{|c|}{ Daftar Ujian / Tes } & + Tambah \\
\hline Show & $10 \vee$ entries & & & & Search: & \\
\hline No & Nama Tes & Mata Pelajaran & $\begin{array}{c}\text { Jumlah } \\
\text { Soal }\end{array}$ & Waktu & Pengacakan Soal & Aksi \\
\hline 1 & $\begin{array}{l}\text { Uts Ilmu DasarKomputer dan } \\
\text { Informasi } \\
\text { Token : ENIIT } \approx\end{array}$ & Bahasa Indonesia & 5 & $\begin{array}{l}27 \text { Jan } 2021 \text { 00:41:00 } \\
\text { (15 menit) }\end{array}$ & Soal diacak & $f$ Edit $\boldsymbol{x}$ Hapus \\
\hline
\end{tabular}

Hasil ujian dapat dilihat gambar 11 berikut :

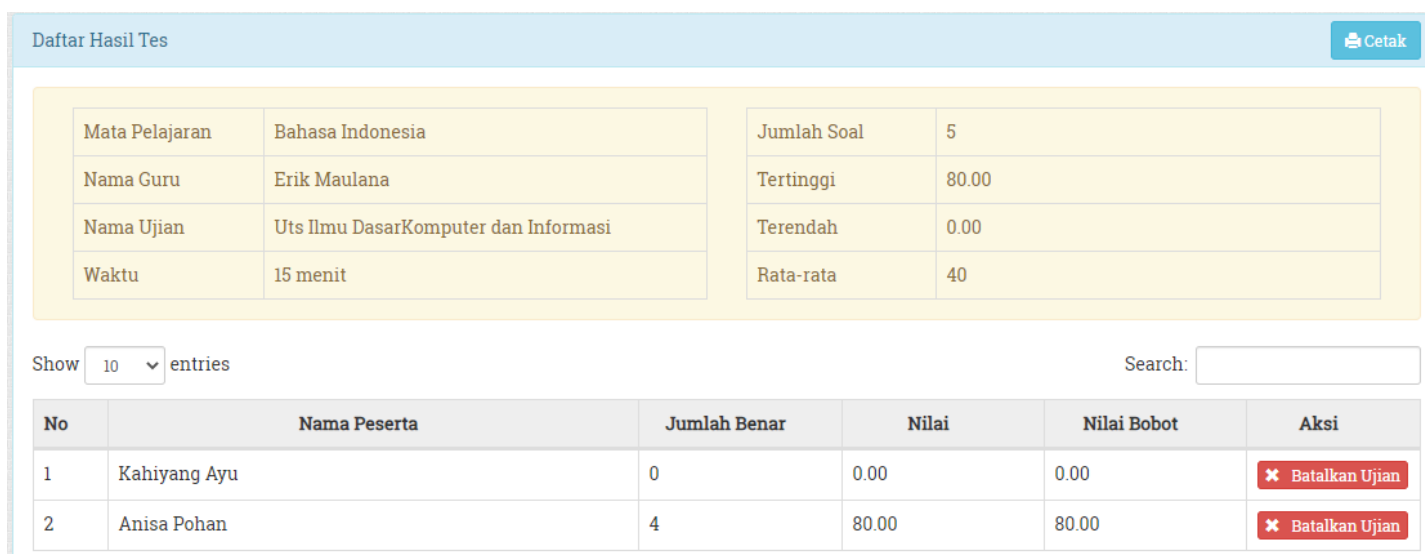

Gambar . Hasil ujian

Siswa

Siswa dalam akun ini login dengan user dan pasword yang diberikan oleh admin. Siswa dalam CBT hanya mengerjakan soal yang telah diisi atau dijadwalkan oleh guru matapelajaran.
Siswa akan diberi token oleh guru matapelajaran untuk bisa mengerakan soal ujian. Berikut bentuk menu ujian dalam akun siswa pada gambar 12 : 


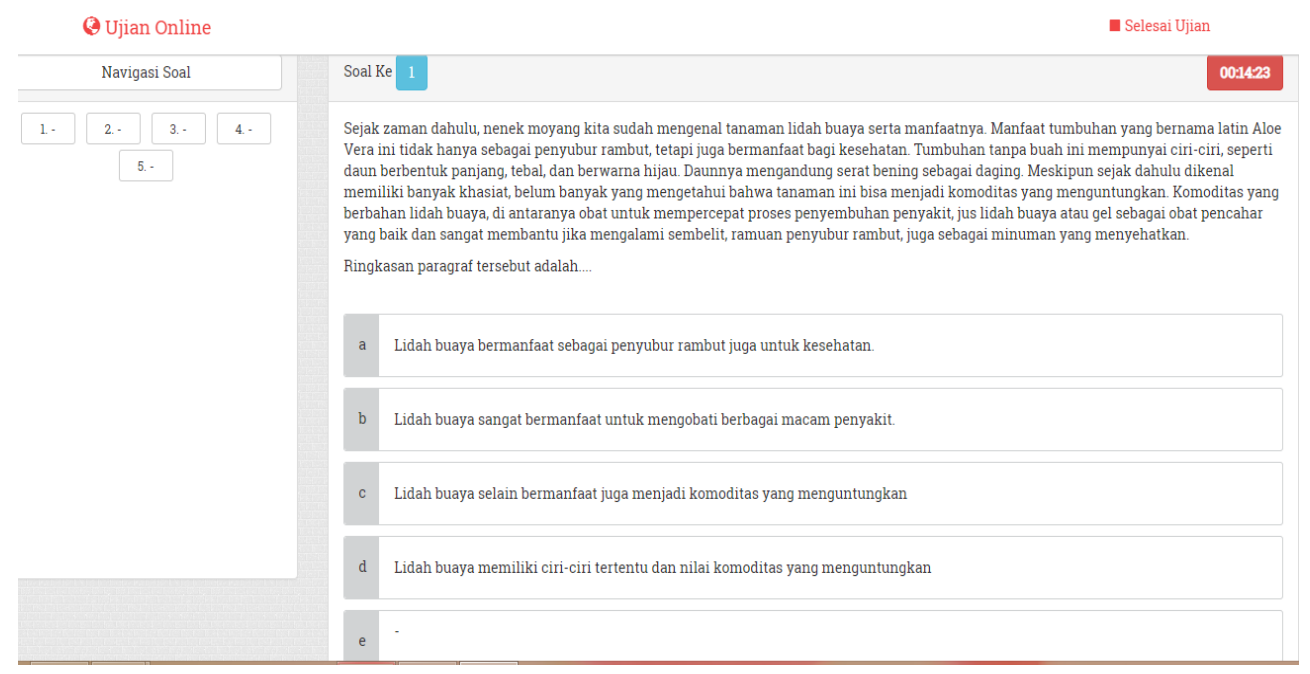

Gambar. Navigasi ujian siswa

Siswa dapat mengerjakan soal sesuai nomor yang berada di kiri atas layar, dalam mengerjakan soal tidak harus urut nomer tersebut. Soal yang telah dikerjakan akan diberi tanda warna merah. Bila sudah selesai mengerjakan soal ujian klik tombol selesai. Selesai ujian secara otomatis bila durasi waktu yang disediakan sudah habis. Setelah selesai ujian akan ada informasi mengenai nilai yang didapat oleh siswa.

Dari pembahasan tersebut di atas semua bagian telah dapat mengerjakan kegiatan CBT masing-masing dengan baik. CBT dapat dijalankan bila semua terpenuhi dengan benar tidak ada kesalahan. Kesalahan dalam memberikan token berakhibat siswa tidak akan bisa masuk ujian sampai penulisan token benar dan sesuai dengan huruf besar dan kecilnya sesuai dengan token yang ditampilkan secara otomatis.

\section{SIMPULAN}

Kesimpulan dalam pengaplikasian teknologi informasi dengan menerapkan ujian berbasi komputer bahwa aplikasi computer base test dapat beroperasi dengan baik, akurat dan tidak berbiaya kertas dan pulsa internet.

Kemudahan dalam mengoperasi aplikasi CBT membawa wawasan baru bahwa teknologi informasi dapat memudahkan dalam pekerjaan sehari-hari khususnya aplikasi CBT yang telah diuji cobakan dengan baik.

\section{DAFTAR PUSTAKA}

PERMENI, Penilaian Hasi Belajar. Penilaian Hasil Belajar oleh Pemerintah dan Penilaian Hasill Belajar oleh Satuan Pendidikan. 3 Indonesia, 2017.

Evaluasi penerapan computer based test (CBT) sebagai upaya perbaikan sistem pada ujian Nasional untuk sekolah terpencil di Sumatra Selatan.

Eka Hartati, Mardiana. 2018, Jurnal MATRIK, p. Vol.18 No. 1.Aplikasi Computer Based Test (CBT) Sebagai Alternatif Evaluasi Hasil Pembelajaran Siswa.

Utami Mizani Putri, Sri Rahayu. 2018, JUSIFO (Jurnal Sistem Informasi), p. Vol 4 No 2 .COMPUTER BASED TEST (CBT) PADA SEKOLAH TINGGI TARAKANITA JAKARTA MENGGUNAKAN METODE COMPUTERIZED FIXED-FORM TEST (CFT). 
Pamungkas, Petrus Dwi Ananto. 2017, JITTER, p. Volume 4 No 1.Penggunaan computer based test (cbt) sebagai sarana evaluasi dan pengaruhnya terhadap efektivitas penilaian pada mata pelajaran sejarah di sma negeri 1 boyolali tahun ajaran 2015/2016.

Dwi Lestari, Akhmad Arif Musadad, Sri Wahyuni. 2019, Jurnal Candi, p. Vol 19 No 1.

UU, Sistem Pendidikan Nasional. Undang Undang Pendidikan Nasional Indonesia. 20 Indonesia, 2003. Undang Undang. 